\title{
Effect of Management Program on Nursing Staff Leading Role and Compliance to Follow Safety Measures at Intensive Care Units
}

\author{
Samah Aboelenein Abdallah', Fouada Mohamed Shabaan ${ }^{2}$, Samar Hosny Ghadery ${ }^{3}$, \\ Maha Eid Shokier ${ }^{4}$ \\ ${ }^{1}$ Assistant lecturer of Nursing Service Administration, Faculty of Nursing, Tanta University \\ ${ }^{2}$ Professor of Nursing Service Administration, Faculty of Nursing, Tanta University \\ ${ }^{3}$ Assistant Professor of Nursing Service Administration, Faculty of Nursing, Tanta University \\ ${ }^{4}$ Lecturer of Nursing Service Administration, Faculty of Nursing, Tanta University
}

\begin{abstract}
Management program on nursing staff leading role and compliance to follow safety measures is an important component help to protect nursing staff from work related risks. Goal of safety program is to keep staff nurses safe and lead them toward safety actions, so they can help them to gain knowledge, and skills to deliver safe and quality care. So, the aim of this study was to determine the effect of management program on nursing staff leading role and compliance to follow safety measures at intensive care units. Study was conducted at all ICUs of Tanta Emergency Hospital. The total number of study sample was $(n=100)$ nursing staff working in ICUs at Tanta Emergency Hospital, including charge nurses $(n=30)$ and bedside nurses ( $\mathrm{n}=70)$. Twoo tools were used for the collection of data: (1) Nursing Staff Performance Scale and (2) Nursing Staff Knowledge Questionnaire. The results of this study revealed that minority $(26.7 \%)$ of charge nurses showed satisfactory level of practice for leading role pre-program, improved to be majority (86.7\%) post-program. Few (41.4\%) bedside nurses had satisfactory level of total compliance to follow safety measures practice pre-program, improved to majority $(88.6 \%)$ post-program. Nursing staff $(48 \%)$ had poor level of total knowledge pre-program, but the majority (92\%) showed good level of total knowledge post program. Conclusion: Nursing staff knowledge and practice on leading role and compliance to follow safety measures in ICUs at Tanta Emergency Hospital were low, change nurses leading role and bedside nurse's compliance practice improved after implementation of needed program. Therefore, the study recommended that conduct regular training programs, workshops and seminars for nursing staff to refresh their knowledge, skills and experiences related to leading role and safety measures.
\end{abstract}

Key words: Bedside nurses, Charge nurses, Compliance, Intensive care units, Knowledge and practice, Leading role, Safety measures. 


\section{Tanta Scientific Nursing Journal}

\section{Introduction}

Today's health care system is growing more complex and challenging. Increased demands for services from better educated personnel to culturally diverse population, higher patient acuity, increased cost saving measures from agencies, increased use of technology and new medications are important factors contributing to this complexity ${ }^{(1)}$. Nursing staff need to be knowledgeable, and skillful to deliver safe and quality care in this complex health care system $^{(2,3)}$. While trying to ensure safe and high quality of patient care, nursing staff are exposed to several work related risks that can cause diseases and accidents ${ }^{(4,5)}$. Intensive care units (ICUs) are independent and closed units, where medical, anesthesiological, surgical, radiological consultant and highly trained nursing staff must be available on a $24 \mathrm{~h}$ per day to provide patients care (6). ICUs environments are highly complex; where nurses face patients requiring high intensity care, heavy workloads, unfamiliar technologies and psychological stressors. ICUs nursing staff must possess specialized body of knowledge, competence and experience to care of critically ill patients and to be able to create high quality and safe work environments ${ }^{(7)}$. Safety is a state in which risks and conditions leading to physical, psychological or material harm are controlled in order to preserve the health and well-being of individuals (8). Incorporating safety measures into daily nursing practices and nursing staff compliance to these measures require an effective charge nurses leading roles to provide them with life-saving and selfdefense actions needs for self-protection and minimizing where possible or eliminating the risks in their workplace ${ }^{(9-1)}$. Leading is a process whereby an individual influences others to accomplish an objective through effective directing, supervising and coordinating ${ }^{(12,13)}$. Directing is an active process of guiding, communicating, and motivating the nursing staff to achieve the outcomes of their performance ${ }^{(10,14)}$. Charge nurses should interpret the safety objectives to the nursing staff and guides them toward the achievement of these objectives, plan and conduct in-service education programs about the work related risk factors and safety measures, and orient the newly posted nursing staff the safety policy and procedures ${ }^{(15)}$. Charge nurses also should communicate to nursing staff all safety rules and guidelines through appropriate way, listen actively to staff problems, respect their ideas, communicate the 


\section{Tanta Scientific Nursing Journal}

pertinent information and work schedules, conduct regular meeting to assess the work related risk factors and informing them in friendly manners the ways of performing their tasks safely and give timely feedback for staff performance ${ }^{(16-18)}$.

Motivating means inspiring the personnel with zeal to do work for the accomplishment of desired objectives ${ }^{(18)}$. Charge nurses should make appropriate use of motivation to enthuse the nursing staff toward the achievement of safety goals. Constantly provide incentives or motivating forces in order to intensify their desire and willingness, regular guidance and counseling, keep appreciation for their achievement, create trustful and helping relationship, and they should positive and enthusiastic role model, listener, supporter and encourager for nursing staff (17). Supervising is a teaching-learning process, which provides constant observation, monitoring, evaluation, and guidance to nursing staff to enable them to perform their activities effectively and efficiently by maintain the required safety standards (10). Charge nurses supervise her staff toward safety through evoking their curiosity and controlling their efforts and other resources to accomplish stated safety objectives ${ }^{(19)}$. Evoking the nursing staff curiosity through helping them to gain insight about the work place risk factors by regular inspection of working units, participate in work place safety decisions, and use of evidence based practice about safety actions ${ }^{(20)}$. Charge nurses should be able to sum up the opinions and viewpoints of nursing staff toward work place safety and able to express them efficiently in safety committee meetings ${ }^{(21,22)}$.

Controlling is the action of seeing the performance of nursing staff to ensure it carried out in accordance to safety standard. Charge nurses need to be regularly assess and maintain the facilities in order to ensure it in good working condition, modifying the work environment to reduce the risk exposure, writing yearly evaluation report and participates in evaluating the safety standards $(23,24)$. Coordinating is ordination of work unit by balancing and keeping the nursing staff working together towards the safety goals ${ }^{(25)}$. Charge nurses must ensure a suitable allocation of needed resources, modifying the work schedules to ensure adequate numbers and mix of nursing staff, and coordinate the work with the other health team members ${ }^{(12)}$.

Nursing staff compliance to safety measures combines the most important aspects of universal precautions designed to reduce the risk of transmission of blood 
borne and other pathogens as handwashing, use of personal protective equipment as (gloves, apron, face mask and eye glasses), safe handling and disposal of sharps, safe handling of laboratory specimen and respiratory protection with proper body mechanics, safe patient handling and lifting and safe handling of equipment in order to reduce the work related risks among nursing staff $(26,27)$. Management program is important to enhance nursing staff knowledge and skills in providing safe and high quality patient's care, further their abilities to plan, communicate, teach, problem solving and decision making. It is an effective method for promoting health and safety of nursing staff and enforcing them to create a- safe work environment and improve quality of care $^{(28)}$.

\section{Aim of the study}

The aim of this study was to determine the effect of management program on nursing staff leading role and compliance to follow safety measures at intensive care units.

\section{Research hypothesis}

Nursing staff leading role and compliance to follow safety measures will be improved after implementation of management program.

\section{Subjects and method}

\section{Research design:}

A quasi experimental research design was used to achieve the aim of the research.

\section{Setting:}

The study was conducted at three intensive care units (ICUs) at Tanta Emergency Hospital namely; Medical ICU, Anesthesia ICU and Medical Emergency ICU.

\section{Subjects:}

The study subject were all $(\mathrm{n}=100)$ nursing staff including charge nurses $(n=30)$ and bedside nurses $(n=70)$ working in the study setting. The subjects were distributed at each of Medical ICU 8 charge nurses \&12 bedside nurses, Anesthesia ICU 10 charge nurses \& 30 bedside nurses, and Medical Emergency ICU 12 charge nurses \& 28 bedside nurses.

\section{Tools of data collection:}

Two tools were used for data collection:

\section{Tool I: Nursing Staff Performance Scale} (practice):

This tool was adopted by the researcher guided by Abidoye et.al, (2016) ${ }^{(29)}$ and Burdorf and Ijzelenberg (2014) ${ }^{(30)}$ and review of recent related literature to assess the nursing staff practice about safety as well as charge nurses leading role. The tool included three parts: 
Part (1): Sociodemographic data of subject. This part included items related to age, sex, marital status, graduation school, working unit, job position, years of experience, number of daily working hours and previous training programs.

Part (2): Charge nurses leading role in managing of nurse's safety observational checklist. This part used to assess the practice of charge nurses leading role responsibilities through 3 subscales, each subscale was consisted of group of items as follows:

1. Directing: was subdivided into 3 subscales: Guidance, communication, and motivation

2. Supervising: was subdivided into 2subscales: Evoke curiosity and controlling

\section{Coordinating}

Part (3): Nurses compliance to follow safety measures observational checklist. This part was used to assess the practice of nurses in compliance to safety measures for control of work related hazards; it included 8 subscales as follows:

- Hand hygiene

- Personal protective equipment was included three parts: wearing gloves, gown, and face, head and foot protection
- Handling sharp instruments

- Handling laboratory specimen

- Respiratory protection

- Safe movement and body mechanics)

- Patient handling and lifting

- Transferring equipment

\section{Scoring system}

Both part (2) the practice of charge nurses leading role and part (3) the nurses compliance to follow safety measures was measured by three points Likert Scale ranging from (1-3): where, always done = (3), sometimes done $=(2)$, not done $=(1)$. The scores were converted into percent scores to assess the level of charge nurses and nurses practice as follows:-

Part (2) scores

- $\quad$ Satisfactory level $\geq 75 \%=$ score from 130.5-174

- Unsatisfactory level $<75 \%=$ score $<$ 130.5

Part (3) scores

- $\quad$ Satisfactory level $\geq 75 \%=$ score from $168.75-225$

- Unsatisfactory level $<75 \%=$ score $<$ 168.75

Tool II: Nursing Staff Knowledge Questionnaire

This tool was adopted by the researcher guided by Clement (2016) ${ }^{(16)}$, Burdorf 


\section{Tanta Scientific Nursing Journal}

and Ijzelenberg (2014) ${ }^{(30)}$ and Gaber (2013) ${ }^{(31)}$ and review of recent related literature to assess the nursing staff knowledge about safety and charge nurses leading role; it included two parts:

Part (1): Identification data

Part (2): Nursing staff knowledge included (50) questions. The form of true $\&$ false included 25 items, multiple choice 20 items and clinical situations 5 items. These questions were classified into 5 categories as follows:

- ICUs work risk factors items included 13 questions.

- Safety measures items included 10 questions.

- Charge nurses leading role responsibilities and training on nursing staff safety items included 6 questions.

- Charge nurse's strategies for leading nursing staff toward safety measures items included 7 questions.

- Importance of nursing staff compliance to safety measures items included 9 questions.

\section{Scoring system}

Each item in the knowledge questionnaire was allotted a score of 2 for correct and complete answer, score of 1 for correct and incomplete answer, and score of zero for wrong answer. The scores were converted into percent scores to assess the levels of nursing staff knowledge as follows:-

- Level of good knowledge $>75 \%=$ score $>75$

- Level of fair knowledge $\quad 60-75 \%=$ score from $60-75$

- Level of poor knowledge $<60 \%$ $=$ score $<60$

\section{Method}

1. An official permission to carry out the study and for implementation of the program, were obtained through a letter issued from the responsible authorities at Faculty of Nursing, Tanta University to medical and nursing directors of Tanta Emergency Hospital, explaining the research aim and procedures. The researcher met with the nursing director of the hospital and supervisors in each ICU. The aim of study and the tools to be used for data collection were explained to obtain their agreement, support and cooperation.

2. Ethical consideration: nursing staff consent to participate in the study was obtained. They were informed about the privacy of information obtained from them, nature of the study, their rights to withdraw, and the confidentiality of their names. 
3. Tools of study were developed by the researcher based on recent related literature.

4. Tool (I) of data collection was tested for its content validity and relevance by a jury of five experts. They were one professor and assistant professor in Medical and Surgical Department, one assistant professor and two lecturers in Nursing Administration Department in Faculty of Nursing, Tanta University. The experts responses were represented in four points rating scales ranging from (4-1); 4 = strongly relevant, $3=$ relevant, $2=$ little relevant, and $1=$ not relevant. Necessary modifications were done, included clarifications, omission of some questions and adding others. The content validity was $96.0 \%$ for charge nurses leading role and $98.0 \%$ for nurse's compliance to follow safety measures.

5. Reliability of tools was tested using Cronbach's Alpha and coefficient test. Its value was 0.92 for charge nurses leading role and 0.94 for nurse's compliance to follow safety measures.

6. A pilot study was conducted on ten nursing staff, 3 charge nurses and 7 bedside nurses, randomly selected and excluded from the subjects; two times to measure test-retest reliability and proposed correction was done.

- The first time aimed to evaluate the content clarity of the tools, relevance, the practicability and feasibility of observation checklist for assessing the nursing staff performance and identifies any obstacles that may be encountered during data collection as confusion about meaning of specific word or item. It also served in determining the time needed to fill the tools.

- The second time two weeks later after the needed correction of statements was done and administered for the same ten nursing staff.

- Test- retest reliability value is 0.94 for charge nurses leading role and 0.96 for nurse's compliance to follow safety measures.

- The pilot study was collected from $1 \mathrm{st}$ February 2018 to 15th February 2018. The administration time for filling questionnaire sheet approximately 45 minutes.

\section{Data collection phase}

- Charge nurses leading role and nurse's compliance to follow safety measures were assessed pre implementation of 


\section{Tanta Scientific Nursing Journal}

management program by tool I. The observation done by the researcher at the clinical setting, each nursing staff was observed for each procedure. The observation span was three hours per day throughout the three shifts.

- Knowledge level of nursing staff about leading role and safety measures was assessed pre implementation of management program by tool II.

- The data was collected by researcher from nursing staff included in the study. The researcher met the subjects in small groups consisted of one to six per each session during their work shifts morning, afternoon or night to distribute the questionnaires. The subjects recorded the answer in the presence of the researcher to ascertain all questions were answered.

8. Management program on nursing staff leading role and compliance to follow safety measures at intensive care units was designed based on review of relevant recent related literature and results of nursing staff knowledge test scores.

\section{Evaluation the effectiveness of the} program is the final step that was planned to determine the extent to which nursing staff subjects have acquired knowledge and practiced it through:
- Pre implementation of the program pre- testing of nursing staff skills performance using (tool I) and level of knowledge using (tool II).

- Post testing of nursing staff level of skills and knowledge after implementation of the program using (tool I \&II).

- Comparison was made between the pre and post-tests results to evaluate change in nursing staff knowledge, charge nurses performance of leading role for nurse's safety actions and nurse's compliance practices.

\section{Statistical analysis}

The collected data were organized, tabulated and statistically analyzed using SPSS software (Statistical Package for the Social Sciences, version 20 SPSS).

\section{Results}

Table (1): shows sociodemographic data of nursing staff. Equal percent (40\%) of nursing staff were from Medical Emergency and Anesthesia ICU, the rest from Medical ICU. Majority (87\%) of nursing staff aged $<30$ years, and the rest aged $\geq 30$ years, with age range 21- 43 years and mean $26.37 \pm 4.5$. Nursing staff $(73 \%)$ were married and the rest were single. Charge nurses constitute $(30 \%)$ and bedside nurses were (70\%). Nursing staff 


\section{Tanta Scientific Nursing Journal}

(44\%) working 12 hours, while (37\%) working 6 hours and only (19\%) working 18 hours per day. High percent $(78 \%)$ of nursing staff not previously attended training programs on safety and infection control. Majority (92\%) of nursing staff were female, $(66 \%)$ graduated from Technical Nursing Institute, the rest were from Faculty of Nursing. Nursing staff $(58 \%)$ were having less than five years of experience with range 1-26 years and mean $5.38 \pm 4.89$.

Figure (1): shows charge nurses level of total practice of leading role in managing nurse's safety pre and post program. Preprogram minority of charge nurses had satisfactory level of total practice of leading role in managing nurse's safety, changed to be majority post-program.

Table (2): illustrates level of charge nurse's practice of total leading role items in managing of nurse's safety pre and post program. There was highly statistically significant improvement of charge nurses level of total practice in all items and total leading role at $(\mathrm{p}=<0.001)$. Pre-program, charge nurses $(86.7 \%)$ showed unsatisfactory level of practice on directing role, decreased to be $23.3 \%$ post program. Beside, charge nurses (73.3\%) showed unsatisfactory level of practice on supervising role pre-program, decreased to be $13.3 \%$ post program. Half $(50 \%)$ of charge nurses showed unsatisfactory level of practice on coordinating role preprogram, decreased to be $3.3 \%$ post program. While, Pre-program 26.7\% of charge nurses had satisfactory level of total leading role practice, improved to $86.7 \%$ post-program.

Table (3): reveals level of charge nurse's total practice of directing leading role subscales in managing of nurse's safety pre and post program. There was highly statistically significant improvement of charge nurses level of total practice in all subscales of directing leading role post program at $(\mathrm{p}=<0.001)$. Pre-program only $(13.3 \%)$ of charge nurses had satisfactory level of total practice of directing leading role, changed to $76.7 \%$ post program. Preprogram, majority (90\%) of charge nurses showed unsatisfactory level of practice on guidance role, decreased to be $33.3 \%$ post program. Charge nurses $(73.3 \%)$ showed unsatisfactory level of practice on communication role pre-program, decreased to be $26.7 \%$ post program. Majority $(80 \%)$ of charge nurses showed unsatisfactory level of practice on motivation role pre-program, decreased to be $16.7 \%$ post program.

Table (4): shows level of charge nurses total practice of supervising leading role 


\section{Tanta Scientific Nursing Journal}

subscales in managing of nurse's safety pre and post program. There was highly statistically significant improvement of charge nurses level of total practice in all subscales of supervising leading role in managing of nurse's safety at $(\mathrm{p}=<0.001)$ post than pre-program. Pre-program only $26.7 \%$ of charge nurses had satisfactory level of total practice of supervising leading role subscales, changed to $86.7 \%$ post program. Pre-program, majority $(83.3 \%)$ of charge nurses showed unsatisfactory level of practice on evoke curiosity, decreased to (36.7\%) post program. Charge nurses (70\%) showed unsatisfactory level of practice on controlling role pre-program, decreased to $(10 \%)$ post program.

Figure (2): shows level of charge nurses practice of total coordinating leading role in managing of nurse's safety pre and post program. Pre-program half of charge nurses had satisfactory level of practice on total coordinating leading role changed to reach the majority post-program.

Table (5): illustrates level of bedside nurses total compliance to safety measures pre and post program. There was highly statistically significant improvement of bedside nurses compliance to all items of safety measures practice post program at $(\mathrm{p}=<0.001)$. Pre-program, bedside nurses $40 \%, 41.4 \%$ and $58.6 \%$ showed satisfactory level of compliance to practice of transferring equipment, patient handling and lifting, hand hygiene, use of personal protective equipment, safe movement and body mechanics and respiratory protection, increased to be $95.7 \%, 94.3 \%, 85.7 \%$, $81.4 \%$ and $80 \%$ post program respectively. Beside, $1.4 \%$ and $30 \%$ of bedside nurses had satisfactory level of compliance to practice of handling laboratory specimen and handling sharp instruments improved to be $100 \%$ and $90 \%$ post program respectively.

Figure (3): shows level of nursing staff total knowledge about safety measures and leading role pre and post program. Preprogram few of nursing staff compared to most of them post-program were at good level of total knowledge about safety measures and leading role.

Figure (4): shows correlation between nursing staff total knowledge and practices about safety measures and leading role pre and post program. There was statistically significant positive correlation between nursing staff total knowledge and practices about safety measures and leading role pre and post-program. 
Table (1): Sociodemographic data of nursing staff $(\mathrm{No}=100)$

\begin{tabular}{|c|c|c|c|c|}
\hline \multirow{2}{*}{ Characteristics } & \multicolumn{2}{|c|}{ Total } & \multirow{2}{*}{$\begin{array}{c}\text { Charge } \\
\text { nurses } \\
\%\end{array}$} & \multirow{2}{*}{$\begin{array}{c}\begin{array}{c}\text { Bedside } \\
\text { nurses }\end{array} \\
\%\end{array}$} \\
\hline & $\mathbf{N}$ & $\%$ & & \\
\hline \multicolumn{5}{|l|}{ Working unit } \\
\hline -Medical Emergency ICU & 40 & 40.0 & 12.0 & 28.0 \\
\hline -Anesthesia ICU & 40 & 40.0 & 10.0 & 30.0 \\
\hline -Medical ICU & 20 & 20.0 & 8.0 & 12.0 \\
\hline \multicolumn{5}{|l|}{ Age (years) } \\
\hline$-<30$ & 87 & 87.0 & 18.0 & 69.0 \\
\hline$-\geq 30$ & 13 & 13.0 & 12.0 & 1.0 \\
\hline Range & \multicolumn{4}{|c|}{$(21-43)$} \\
\hline Mean \pm SD & \multicolumn{4}{|c|}{$26.37 \pm 4.5$} \\
\hline \multicolumn{5}{|l|}{ Marital status } \\
\hline -Single & 27 & 27.0 & 5.0 & 22.0 \\
\hline -Married & 73 & 73.0 & 25.0 & 48.0 \\
\hline \multicolumn{5}{|l|}{ Job position } \\
\hline -Charge Nurse & 30 & 30.0 & 30.0 & - \\
\hline -Bedside Nurse & 70 & 70.0 & - & 70.0 \\
\hline \multicolumn{5}{|l|}{ Number of daily working hours } \\
\hline-6 & 37 & 37.0 & 2.0 & 35.0 \\
\hline-12 & 44 & 44.0 & 21.0 & 23.0 \\
\hline-18 & 19 & 19.0 & 7.0 & 12.0 \\
\hline \multicolumn{5}{|c|}{$\begin{array}{l}\text { Attend previous programs on safety } \\
\text { and infection control }\end{array}$} \\
\hline -Yes & 22 & 22.0 & 5.0 & 17.0 \\
\hline -No & 78 & 78.0 & 25.0 & 53.0 \\
\hline \multicolumn{5}{|l|}{ Sex } \\
\hline -Female & 92 & 92.0 & 26 & 66.0 \\
\hline -Male & 8 & 8.0 & 4 & 4.0 \\
\hline \multicolumn{5}{|l|}{ Graduation school } \\
\hline - Faculty of Nursing & 34 & 34.0 & 23.0 & 11.0 \\
\hline - Technical Nursing Institute & 66 & 66.0 & 7.0 & 59.0 \\
\hline \multicolumn{5}{|l|}{ Years of experience (years) } \\
\hline$-1-<5$ & 58 & 58.0 & 6.0 & 52.0 \\
\hline$-5-<10$ & 30 & 30.0 & 14.0 & 16.0 \\
\hline - 10 or more & 12 & 12.0 & 10.0 & 2.0 \\
\hline Range & \multicolumn{4}{|c|}{$1-26$} \\
\hline Mean \pm SD & \multicolumn{4}{|c|}{$5.38 \pm 4.89$} \\
\hline
\end{tabular}




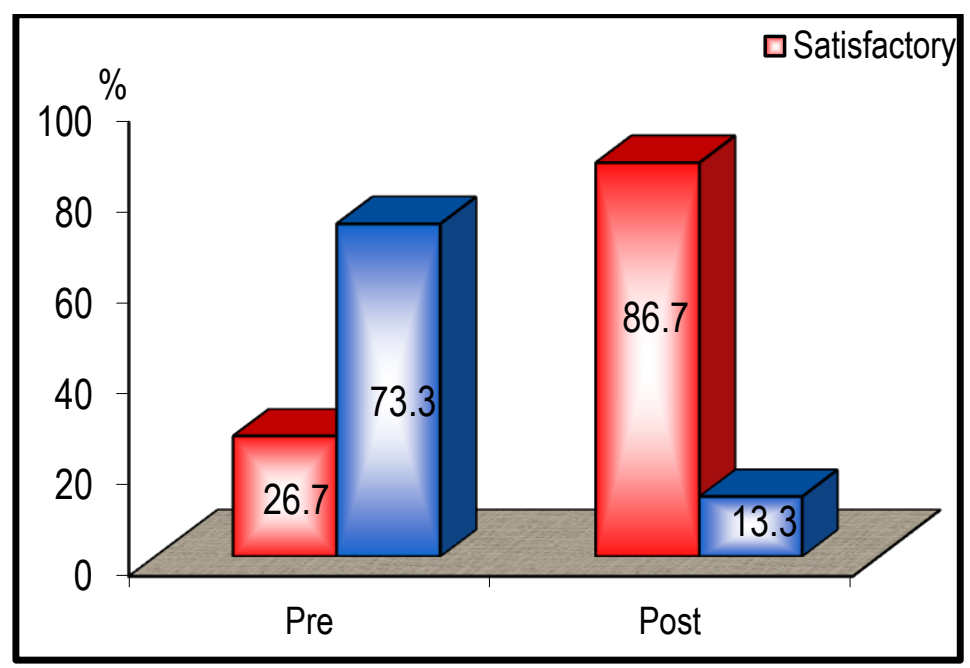

Figure (1): Charge nurses level of total practice of leading role in managing nurse's safety pre and post program $(\mathrm{No}=30$

Table (2): Level of charge nurses practice of total leading role items in managing of nurse's safety pre and post program $(\mathrm{No}=30)$

\begin{tabular}{|c|c|c|c|c|c|c|c|}
\hline \multirow{2}{*}{$\begin{array}{c}\text { Items of leading } \\
\text { role }\end{array}$} & \multirow{2}{*}{ Levels } & \multicolumn{2}{|c|}{ Pre } & \multicolumn{2}{|c|}{ Post } & \multirow{2}{*}{$\mathbf{X}^{2}$} & \multirow{2}{*}{ P-value } \\
\hline & & $\mathbf{N}$ & $\%$ & $\mathbf{N}$ & $\%$ & & \\
\hline \multirow{2}{*}{ - Directing } & Satisfactory & 4 & 13.3 & 23 & 76.7 & \multirow{2}{*}{24.310} & \multirow{2}{*}{$<0.001 * *$} \\
\hline & Unsatisfactory & 26 & 86.7 & 7 & 23.3 & & \\
\hline \multirow{2}{*}{ - Supervising } & Satisfactory & 8 & 26.7 & 26 & 86.7 & \multirow{2}{*}{21.991} & \multirow{2}{*}{$<0.001 * *$} \\
\hline & Unsatisfactory & 22 & 73.3 & 4 & 13.3 & & \\
\hline \multirow{2}{*}{ - Coordinating } & Satisfactory & 15 & 50.0 & 29 & 96.7 & \multirow{2}{*}{16.705} & \multirow{2}{*}{$<0.001 * *$} \\
\hline & Unsatisfactory & 15 & 50.0 & 1 & 3.3 & & \\
\hline \multirow{2}{*}{ - Total } & Satisfactory & 8 & 26.7 & 26 & 86.7 & \multirow{2}{*}{21.991} & \multirow{2}{*}{$<0.001 * *$} \\
\hline & Unsatisfactory & 22 & 73.3 & 4 & 13.3 & & \\
\hline
\end{tabular}

** Highly significant at $\mathbf{P}<0.01$ 


\section{Tanta Scientific Nursing Journal}

Table (3): Level of charge nurses total practice of directing leading role subscales in managing of nurse's safety pre and post program $(\mathrm{No}=30)$

\begin{tabular}{|c|c|c|c|c|c|c|c|c|c|}
\hline \multirow{3}{*}{ subscales items } & \multicolumn{4}{|c|}{ Pre-program $(n=30)$} & \multicolumn{4}{|c|}{ Post-program $(n=30)$} & \multirow{3}{*}{$\begin{array}{c}\mathbf{X}^{\mathbf{2}} \\
\text { (P-value) }\end{array}$} \\
\hline & \multicolumn{2}{|c|}{ Satisfactory } & \multicolumn{2}{|c|}{ Unsatisfactory } & \multicolumn{2}{|c|}{ Satisfactory } & \multicolumn{2}{|c|}{ Unsatisfactory } & \\
\hline & $\mathbf{N}$ & $\%$ & $\mathbf{N}$ & $\%$ & $\mathbf{N}$ & $\%$ & $\mathbf{N}$ & $\%$ & \\
\hline - Guidance & 3 & 10.0 & 27 & 90.0 & 20 & 66.7 & 10 & 33.3 & $\begin{array}{c}20.376 \\
(<0.001 * *)\end{array}$ \\
\hline - Communication & 8 & 26.7 & 22 & 73.3 & 22 & 73.3 & 8 & 26.7 & $\begin{array}{c}13.067 \\
(<0.001 * *)\end{array}$ \\
\hline - Motivation & 6 & 20.0 & 24 & 80.0 & 25 & 83.3 & 5 & 16.7 & $\begin{array}{c}24.093 \\
(<0.001 * *)\end{array}$ \\
\hline - Total level & 4 & 13.3 & 26 & 86.7 & 23 & 76.7 & 7 & 23.3 & $\begin{array}{c}24.310 \\
(0.001 * *)\end{array}$ \\
\hline
\end{tabular}

** Highly significant at $\mathbf{P}<0.01$

Table (4): Level of charge nurses total practice of supervising leading role subscales in managing of nurse's safety pre and post program $(\mathrm{No}=30)$

\begin{tabular}{|c|c|c|c|c|c|c|c|c|c|}
\hline \multirow{3}{*}{$\begin{array}{l}\text { Supervising } \\
\text { leading role } \\
\text { subscales }\end{array}$} & \multicolumn{4}{|c|}{ Pre-program $(n=70)$} & \multicolumn{4}{|c|}{ Post-program (n=70) } & \multirow{3}{*}{$\begin{array}{c}\text { X2 } \\
\text { (P-value) }\end{array}$} \\
\hline & \multicolumn{2}{|c|}{ Satisfactory } & \multicolumn{2}{|c|}{ Unsatisfactory } & \multicolumn{2}{|c|}{ Satisfactory } & \multicolumn{2}{|c|}{ Unsatisfactory } & \\
\hline & $\mathbf{N}$ & $\%$ & $\mathbf{N}$ & $\%$ & $\mathbf{N}$ & $\%$ & $\mathbf{N}$ & $\%$ & \\
\hline - Evoke curiosity & 5 & 16.7 & 25 & 83.3 & 23 & 76.7 & 7 & 36.7 & $\begin{array}{c}21.696 \\
(<0.001 * *)\end{array}$ \\
\hline - Controlling & 9 & 30.0 & 21 & 70.0 & 27 & 90.0 & 3 & 10.0 & $\begin{array}{c}22.500 \\
(<0.001 * *)\end{array}$ \\
\hline - Total level & 8 & 26.7 & 22 & 73.3 & 26 & 86.7 & 4 & 13.3 & $\begin{array}{c}2.232 \\
(<0.001 * *)\end{array}$ \\
\hline
\end{tabular}

** Highly significant at $\mathbf{P}<0.01$ 


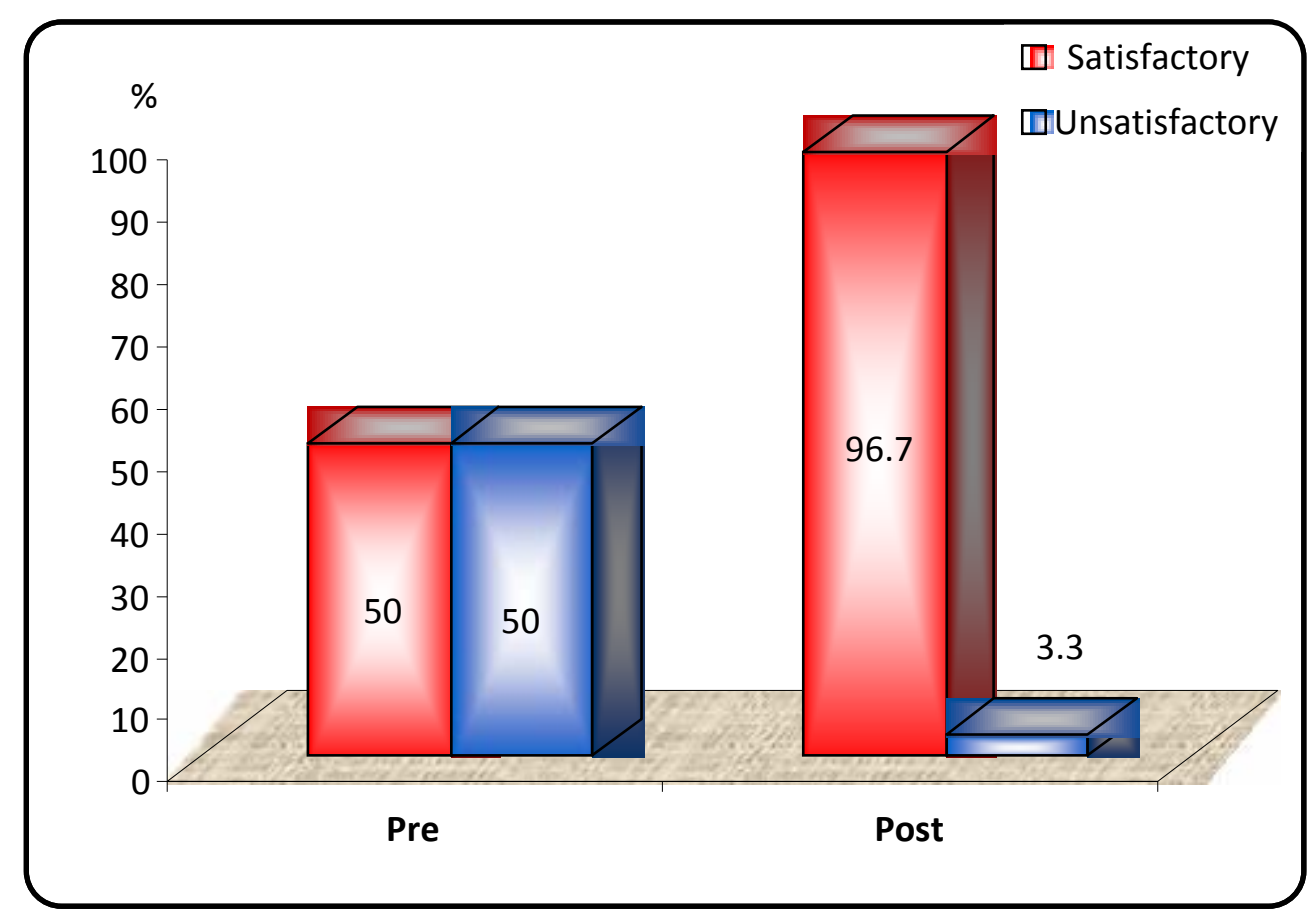

Figure (2): Level of charge nurses practice of total coordinating leading role in managing of nurse's safety pre and post program $(\mathrm{No}=30)$ 
Table (5): Level of bedside nurses total compliance to safety measures pre and post program $(\mathrm{No}=70)$.

\begin{tabular}{|c|c|c|c|c|c|c|}
\hline \multirow{2}{*}{$\begin{array}{l}\text { Items of bedside nurses } \\
\text { compliance }\end{array}$} & \multirow{2}{*}{ Level } & \multicolumn{2}{|c|}{ Pre } & \multicolumn{2}{|c|}{ Post } & \multirow{2}{*}{$\begin{array}{c}\mathrm{X}^{2} \\
\text { (p-value) }\end{array}$} \\
\hline & & $\mathbf{N}$ & $\%$ & $\mathbf{N}$ & $\%$ & \\
\hline \multirow{2}{*}{-Hand hygiene } & Satisfactory & 29 & 41.4 & 67 & 95.7 & \multirow{2}{*}{$\begin{array}{c}47.860 \\
(<0.001 * *)\end{array}$} \\
\hline & Unsatisfactory & 41 & 58.6 & 3 & 4.3 & \\
\hline \multirow{2}{*}{$\begin{array}{l}\text {-Personal protective } \\
\text { equipment }\end{array}$} & Satisfactory & 29 & 41.4 & 60 & 85.7 & \multirow{2}{*}{$\begin{array}{c}29.641 \\
(<0.001 * *)\end{array}$} \\
\hline & Unsatisfactory & 41 & 58.6 & 10 & 14.3 & \\
\hline \multirow{2}{*}{$\begin{array}{ll}\text {-Handling } & \text { sharp } \\
\text { instruments } & \end{array}$} & Satisfactory & 21 & 30.0 & 63 & 90.0 & \multirow{2}{*}{$\begin{array}{c}\mathbf{5 2 . 5 0 0} \\
(<0.001 * *)\end{array}$} \\
\hline & Unsatisfactory & 49 & 70.0 & 7 & 10.0 & \\
\hline \multirow{2}{*}{$\begin{array}{l}\text {-Handling laboratory } \\
\text { specimen }\end{array}$} & Satisfactory & 1 & 1.4 & 70 & 100 & \multirow{2}{*}{$\begin{array}{c}136.056 \\
(<0.001 * *)\end{array}$} \\
\hline & Unsatisfactory & 69 & 98.6 & 0 & 0.0 & \\
\hline \multirow{2}{*}{ - Respiratory protection } & Satisfactory & 41 & 58.6 & 66 & 94.3 & \multirow{2}{*}{$\begin{array}{c}24.781 \\
(<0.001 * *)\end{array}$} \\
\hline & Unsatisfactory & 29 & 41.4 & 4 & 5.7 & \\
\hline \multirow{2}{*}{$\begin{array}{l}\text {-Safe movement and } \\
\text { body mechanics }\end{array}$} & Satisfactory & 29 & 41.4 & 56 & 80.0 & \multirow{2}{*}{$\begin{array}{c}21.831 \\
(<0.001 * *)\end{array}$} \\
\hline & Unsatisfactory & 41 & 58.6 & 14 & 20.0 & \\
\hline \multirow{2}{*}{$\begin{array}{l}\text {-Patient handling and } \\
\text { lifting }\end{array}$} & Satisfactory & 28 & 40.0 & 67 & 95.7 & \multirow{2}{*}{$\begin{array}{c}49.811 \\
(<0.001 * *)\end{array}$} \\
\hline & Unsatisfactory & 42 & 60.0 & 3 & 4.3 & \\
\hline \multirow{2}{*}{$\begin{array}{l}\text {-Transferring } \\
\text { equipment }\end{array}$} & Satisfactory & 28 & 40.0 & 57 & 81.4 & \multirow{2}{*}{$\begin{array}{c}25.185 \\
(<0.001 * *)\end{array}$} \\
\hline & Unsatisfactory & 42 & 60.0 & 13 & 18.6 & \\
\hline \multirow{2}{*}{ Total } & Satisfactory & 29 & 41.4 & 62 & 88.6 & \multirow{2}{*}{$\begin{array}{c}34.192 \\
(<0.001 * *)\end{array}$} \\
\hline & Unsatisfactory & 41 & 58.6 & 8 & 11.4 & \\
\hline
\end{tabular}




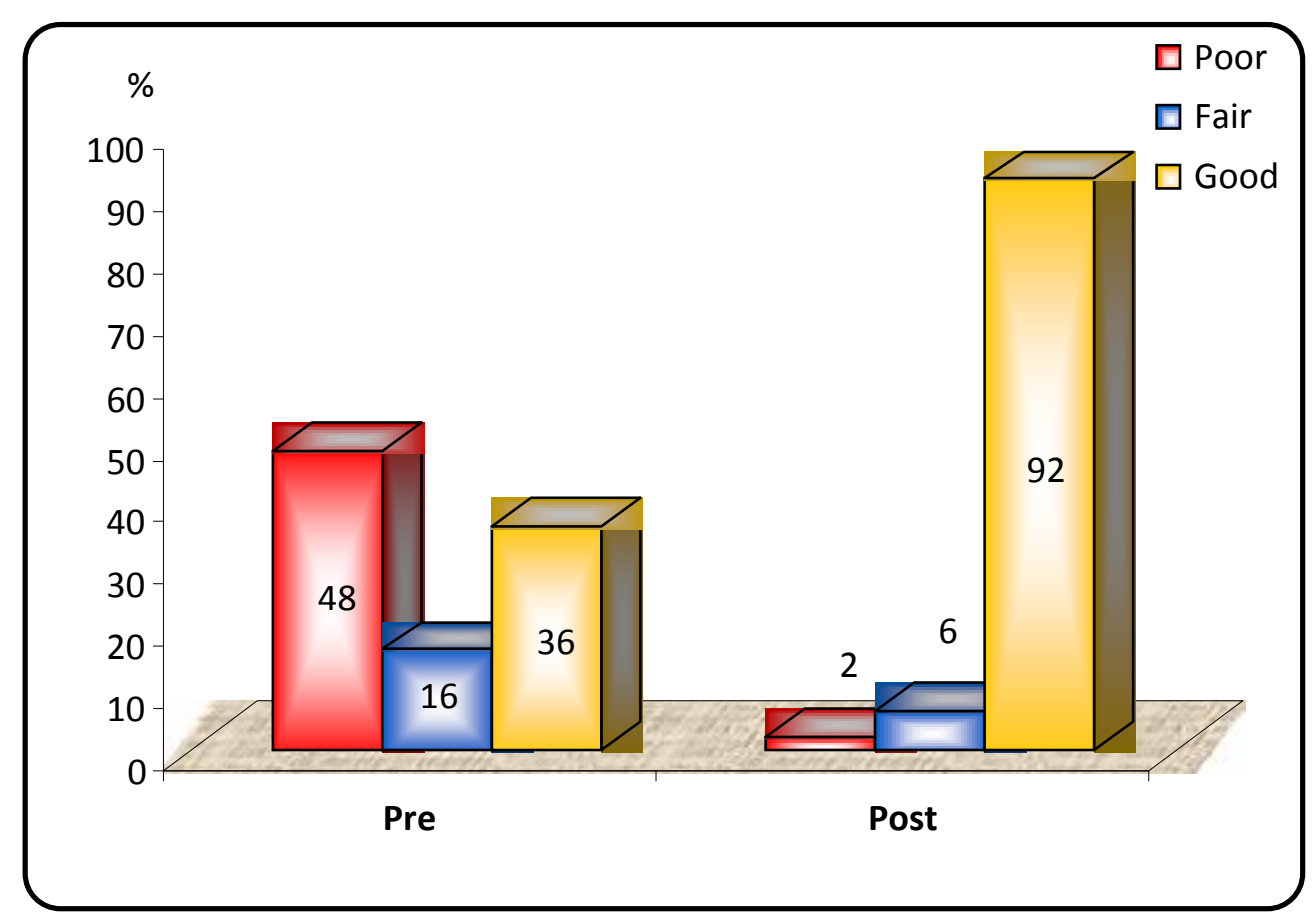

Figure (3): Level of nursing staff total knowledge about safety measures and leading role pre and post program $(\mathrm{No}=100)$

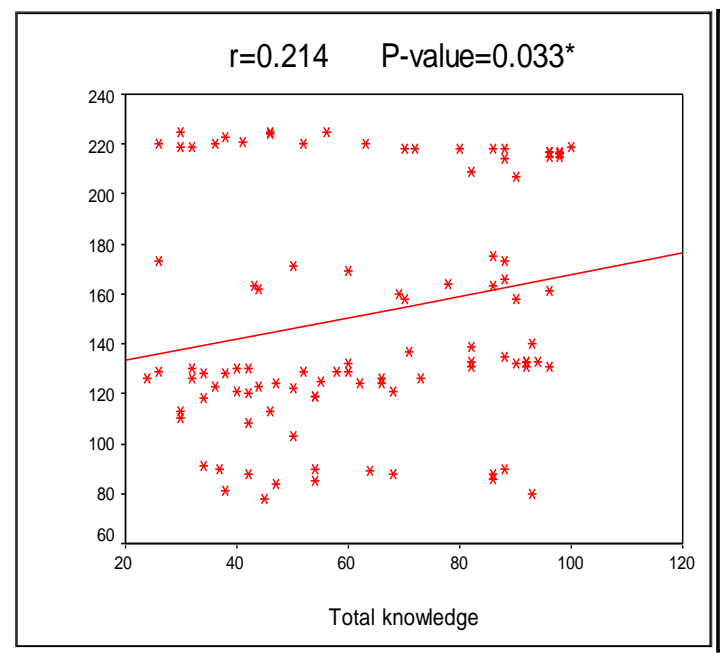

Pre-program

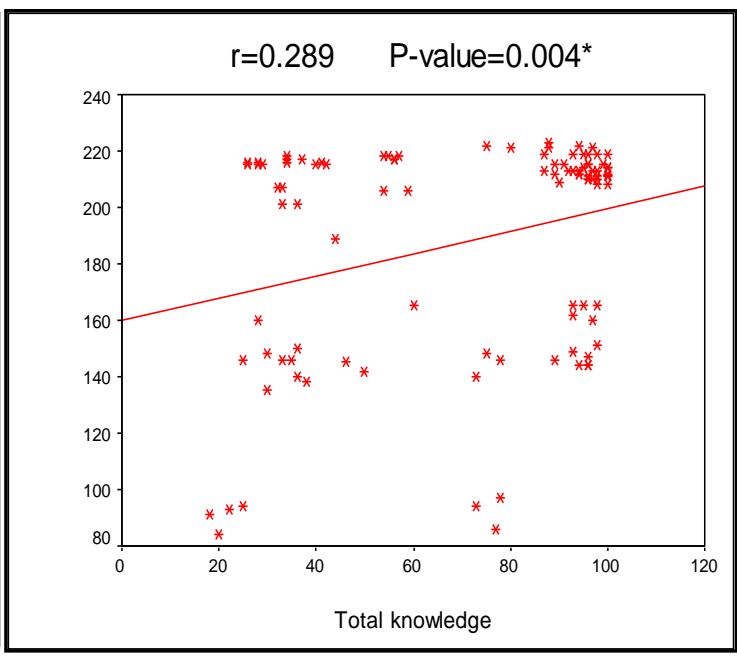

Post-program

Figure (4): Correlation between nursing staff total knowledge and practices about safety measures and leading role pre and post program $(\mathrm{No}=100)$ 


\section{Tanta Scientific Nursing Journal}

\section{Discussion}

Present study finding revealed that minority of charge nurses had satisfactory level of total practice of leading role in managing nurse's safety pre-program. Since they showed unsatisfactory practice of directing, supervising and coordinating items of leading role. Beside they not attend previous training programs and lack knowledge about basic activities for leading nursing staff toward safety measures. Really those charge nurses need sufficient knowledge and training about their responsibilities to professionally lead nursing staff toward correct safety actions. Theoretically speaking all charge nurses need to be prepared with special skills through orientation programs before hold their leadership role to accomplish their role duties and responsibilities. Gad (2013) ${ }^{(32)}$ study about the administrative duties of baccalaureate nursing graduate unit manager, supported present study result and showed that more than half of charge nurses not attend educational programs relevant to professional interest and not improve self-professional knowledge and competence. Also, Youssef (2017) (33) study about common occupational hazards facing nursing staff at Tanta University Hospital, and Neves et al (2011) $^{(34)}$ study about safety of nursing staff and determinants of adherence to personal protective equipment, both studies indicated that charge nurses don't practice their leading role for directing staff nurses toward safety due to their knowledge deficiency and improper training.

Current study results revealed that preprogram few of charge nurses had satisfactory level of practice on total directing leading role. Those charge nurses showed unsatisfactory level of practice on guidance, communication and motivation role. Actually they failed to be role model and not direct staff nurses for performing safety measures. While they are responsible to exhibit guiding, motivational and supportive behaviors consistent with their staff nurses needs and potentials. Ideally they required to pay attention for ensuring open channel of communication and giving positive and negative feedback as well as continuous encouragement to staff nurses to prevent hazards exposure. White (2017) ${ }^{(35)}$ study about the impact of charge nurse transformational leadership: workshops in reducing patient falls, supported present study findings and showed that more than half of nurses reported lack of direction and training from charge nurses in promoting patients and nurses safety pre intervention implementation. Also, 


\section{Tanta Scientific Nursing Journal}

Sherman et al (2011) (9) study about charge nurse perspectives on frontline leadership in acute care environments, indicated that most of charge nurses showed lack of direction activities and guidance for nursing staff due to lack of their competency and educational preparation. As well as, Abd Elaziz (2010) (36) study about effect of training on the head nurses managerial skills related to the organizing and directing, revealed that majority of nurse supervisors didn't provide direction, guidance or proper training for staff development. In contrast, Gad (2013) ${ }^{(32)}$ not support the present study findings and revealed that, more than ninety percent of charge nurses performed directing activities in the work unit. She asserted that, those nurse supervisors are successful leaders carrying out their functions depending on appropriate communication and delegation skills, providing them with regular directions, guidance and motivation.

Results revealed that pre-program minority of charge nurses showed satisfactory level of practice on total supervising leading role for managing staff nurses safety. They cannot evoke staff nurses curiosity and cannot fulfil the activities of their controlling leading role. May be those charge nurses overlook the high complexity and risks of intensive care units area, so they require educational programs to remind them and improve their knowledge and practice to supervise their staff nurses and lead them to manage their dangerous work related hazards. As well as to enable them to create safe work environments and reduce work related risks that induced by their insufficient knowledge and practice. Youssef (2017) ${ }^{(33)}$ supported the present study findings and revealed that more than half of nursing staff reported that charge nurses do not practice supervision and evaluation for work related hazards due to knowledge deficiency and improper training in this area. She asserted that charge nurses required doing supervision from time to time to discover and direct staff nurses for proper prevention. Clark (2016) ${ }^{(37)}$ also reported that failures to adhere to rules and regulations, not follow safety procedures conscientiously and not take precautions against hazards are commonplace in many health care organizations as a result of lack of supervision.

Data revealed that half of charge nurses showed satisfactory level of practice of total coordinating leading role for managing of staff nurses safety preprogram. Actually those charge nurses were not promoting enough numbers and 


\section{Tanta Scientific Nursing Journal}

mix of staff nurses at day or night shifts. They not organize for promoting rest time for nurses during work and not fairly distribute daily work between them. Also, they not coordinate work with human resources department and not make enough supplies and equipment available for staff nurses. Those charge nurses should pay their attention for their responsibility for identifying staff nurses needs of resources and ensure its availability to meet these needs, and to ensure that the ICU is properly stocked with needed supplies and materials. Sabra and Morsy (2016) (38) added that charge nurses should identify factors that contribute to sources of occupational hazards and develop appropriate coordinating strategies to promote staff safety. El-Atroush (2010) (39) supported present study result and revealed that most of nurse interns reported that charge nurses not provide enough staff nurses or enough supplies and equipment to protect them from work related hazards. But findings of this study are not consistent with Gad (2013) ${ }^{(32)}$ who emphasized that, charge nurses are clever nurse supervisors, they make coordination for clinical and administrative resources with human resources department, other departments and institutions.
Current study results revealed that few bedside nurses showed satisfactory level of total compliance to follow safety measures pre-program. Actually bedside nurses revealed lack of knowledge about the importance of their compliance to follow safety measures. Apparently those bedside nurses showed need to understand the risks at ICU work place and to value the importance to follow safety measures for reducing their risks. Also, they need to be enforced by educational training program to improve their knowledge and training to improve their level of compliance with safety measures. Gammon et al (2017) ${ }^{(40)}$ conducted a review of the evidence for suboptimal compliance of healthcare practitioners to standard/universal infection control precautions and Labrague et al (2012) ${ }^{(41)}$ study about knowledge of and compliance with standard precautions among student nurses, both studies supported present findings and reported that healthcare workers have poor compliance to safety measures due to lack of knowledge and training.

Finding illustrated that pre-program, most of nursing staff showed poor level of knowledge about safety measures and leading role. Most probably that low level of knowledge due to staff and charge 


\section{Tanta Scientific Nursing Journal}

nurses overlooking for ICUs work risk factors, noncompliance to safety actions, and inadequacy of charge nurses leading role toward safety measures. They were in need for appropriate educational programs to facilitate acquisition, updating, improve and correct their knowledge. Keorekile (2015) ${ }^{(2)}$ supported present study finding and reported that the majority of nurses indicated that they did not have adequate knowledge of occupational health and safety pre intervention implementation. Also, Adly et al (2014) ${ }^{(42)}$ found more than two thirds of studied nurses had low level of knowledge about standard precautions of infection control in Pediatric Critical Care Units pre-program implementation. Beside, Nkoko et al (2014) ${ }^{(43)}$ study about reducing the risks to health care workers from blood and body fluid exposure in a small rural hospital, found low level of knowledge about work place safety among nurses at rural hospitals in South Africa. But, Aluko et al (2016) (44) study about a survey on knowledge, attitudes and perceptions of occupational hazards and safety practices in Nigeria health care workers, not support present study finding and revealed that most respondents had high knowledge rating about occupational hazards and safety practices.
Present study finding revealed that there were statistically significant positive correlation between nursing staff total knowledge and practices score about safety measures and leading role pre and post program. This finding highlights the need of knowledge as a pre requisite for practice improvement. Those nursing staff now know that accurate information is essential to leading role and safety performance to protect them from most of work related risks that exposed in daily ICUs work. EIAshmawy (2017) ${ }^{(45)}$ supported the present finding and revealed that there was significant positive correlation between knowledge and performance of the study group about safety strategies for controlling and management of needle stick injuries pre, immediately and three months after strategy implementation. Also, Niu (2015) ${ }^{(46)}$ study on occupational safety and health in the health care sector, revealed that there is a link between poor or inadequate knowledge and poor occupational safety performance. Similar findings were also reported by KatzNavon et al (2105) ${ }^{(47)}$ study about safety climate in health care organizations: A multidimensional approach, they found that significant positive correlation between nurse supervisor's safety knowledge and performance and nursing staff compliance performance. This study 


\section{Tanta Scientific Nursing Journal}

supports the idea that workplace safety knowledge is associated with higher compliance with safety practices.

Finally, the present study highlights that the implementation of current management training program was succeed as mean for improving nursing staff knowledge and practice. That program assisted those charge nurses to perform their effective leading role for managing of staff nurses safety, as well as improving the bedside nurse's compliance to safety measures for patients and to protect themselves from work risks. Therefore, hospitals need to take serious actions to provide support and resources for nursing staff in the form of educational and training opportunities designed to improve their leading role and compliance to safety measures. Provide amentor for nursing staff and to maintain periodical re-education about evidence based safety practices.

\section{Conclusion}

Nursing staff at ICUs of Tanta Emergency Hospital were at low level of knowledge and performance in safety measures preprogram. There were lacking of charge nurses leading role and staff nurses compliance to follow safety measures. But implementing of well-designed management program significantly improved their knowledge and performance for leading role and compliance to follow safety measures. Charge nurses and bedside nurses permanently need for enforced orientation program pre-employment and periodical in-service training programs to help develop charge nurses skills of leading role and bedside nurses regular follow up to improve their safety compliance.

\section{Recommendation}

Based on the findings of the current study, the following recommendations are derived and suggested:

1. Raise the awareness of nursing staff about ICUs work related safety measures.

2. Attention to conducting regular workshops to enforce charge nurses leading role to follow safety measures.

3. Newly posted nursing staff should attend orientation programs about ICUs work related safety measures.

4. Periodical in-service training programs for nursing staff about work related safety measures.

5. Advertise safety policies and rules to be available in each ICU.

6. Infection control committee in the hospital required to have an active role in controlling work environment related risks.

7. Prime importance ICUs equipped 24 hours with sufficient supplies, equipment and experienced trained nurses on work related safety. 


\section{References}

1. National Advisory Council on Nurses Education and Practice. Meeting the challenge of the new millennium: Challenges facing the nurse workforce in a changing health care environment. Six annual reports. 2010.

2. Keorekile O. Occupational Health Hazards Encountered by Nurses at Letsholathebe II Memorial Hospital in Manu, Botswana. Master Thesis. University of Limpopo, South Africa, Faculty of Health Science. 2015.

3. Chhabra S. Health hazards among health care personnel. Journal of Mahatma Gandhi Institute of Medical Science. 2016; 21(1): 10-24.

4. Lima L, Oliveira C and Rodrigues K. Occupational exposure to biological material at the Hospital Santa Casa de Pelotas 2004 to 2008. Esc Anna Nery Rev Enferm. 2011; 15(1): 96-102.

5. Valentin A, Ferdinande $\mathrm{P}$ and Esicm. Recommendations on basic requirements for intensive care unit: Structural and organizational aspects. Intensive Care Med. 2011; 37(10): 1575-87.

6. Obied H. Application of Designed Orientation Program for Nurse Interns Based on Learning Needs Assessment.
Doctoral Thesis. Tanta University, Faculty of Nursing. 2013. 5.

7. Mendonça D, Oliveira A, Tavares A, Neto A, Souza V and Rosendo R. Profile accidents involving nurses in the intensive care environment. Enfermería Global. 2015; 39(1): 211-116.

8. Subramaniam C, Shamsudin F, Zin M and Lazim H. Do workplace safety practices influence safety compliance behavior? Evidence among nurses in Malaysia. ANZAM 2013. 1-15. http://www.anzam.org/wp-content/ uploads/pdf-manager/150_ANZAM2013-328.PDF

9. Sherman R, Schwarzkopf R, and Kiger A. Charge nurse perspectives on frontline leadership in acute care environments. International Scholarly Research Network. 2011; 21(1): 1-8.

10. Basavanthappa B. Bursing Administration. New Delhi: Jaypee Brothers Medical Publisher. 3rd ed; 2014: 741-746.

11. Evans L, Sunley K and Barrett S. Essential practice for infection prevention and control: Guidance for nursing staff. Royal College of Nursing. London, 2012: 9-32.

12. Eid W. Enforcement Educational Management Program on Autonomous 


\section{Tanta Scientific Nursing Journal}

Decision Making Among Novice

Graduate Nurses. Doctoral Thesis.

Tanta University, Faculty of Nursing. 2016; 31.

13. Noe R, Hollenbeck J, Gerhart B, and Wricht P. Human Resources Management: Gaining A Competitive Advantage. McGraw Hill Education. 9th ed; 2015: 143-147.

14. Northouse P. Leadership Theory \& Practice. London: Sage Publication, inc. 7th ed; 2016: 6-12.

15. Gysbers N. The importance of state guidance leadership for the $21 \mathrm{st}$ century: Recommendations for improvement. National Consortium of State Guidance Leadership. Singer Island; 2011.

16. Clement N. Essentials of Management of Nursing Service and Education. London: The Health Science Publisher. 1st ed; 2016: 238-247.

17. Pereira F, Toffano S, Silva A, Canini S and Gir E. Adherence to standard precautions of nurses working in intensive care at a university hospital. Rev Esc Enferm USP 2013; 47(3): 681-7.

18. Marquis B and Huston C. Leadership Roles \& Management Functions In Nursing: Theory and Application. China: Wolters Kluwer Health Publisher. 8th ed; 2015: 414-438.
19. Ali A. The role of leadership in human resource management: Proposing conceptual framework of advanced leadership model. Interdisciplinary Journal of Contemporary Research in Business. 2012; 4(6): 976-989.

20. Johnson W. L. Serious use of a serious game for language learning. International Journal of Artificial Intelligence in Education. 2010; 20(1): 175-195.

21. Smith H. Curiosity, Knowledge and Liberty. Exploring the Lived Reality of Curiosity in Nursing Practice. PhD thesis. University of Leeds. 2015.

22. Melanie A. Nursing leadership role in translating research to practice. Journal of Emergency Nursing: JEN; Philadelphia. 2014; 40(2): 114.

23. A Garg and Kapellusch J. "Long-term efficacy of an ergonomics program that includes patient-handling devices on reducing musculoskeletal injuries to nursing personnel," human factors. The Journal of the Human Factors and Ergonomics Society.2012; 54(4): 608-62.

24. Bally J. The role of nursing leadership in creating a mentoring culture in acute care environment. Nurse Economic Summit. Washington, DC. Journal for Health Care Leader. 2012; 25(3): 143-149. 
25. Murry M and Langan J. Leadership and Management in Nursing. Boston: Pearson Publisher. 1st ed; 2011: 77-98.

26. Australian Commission On Safety And Quality In Health Care. Australian guidelines for the prevention and control of infection in healthcare. 2010: 33-90

27. Smolowitz J, Speakman E, Wojnar D, Whelan E, Ulrich S, Hayes C and Wood L. Role of the registered nurse in primary health care: Meeting health care needs in the 21 st century. Nursing Outlook. Elsevier Inc. 2015; 63(2): 130-136.

28. Corcoran A, Casserly M, Price-Baugh R, Walston D, Hall R and Simon C. Rethinking leadership: The changing role of principal supervisors. Council of the Great City Schools. 2013; 24-35.

29. Abidoye A, Adebisi T, Aluko O, Ewegbemi M, and Popoola B. Knowledge, attitudes and perceptions of occupational hazards and safety practices in Nigerian healthcare workers. BMC Research Notes. 2016; 9(1): 71 .

30. Burdorf A and Ijzelenberg W. Risk factors for musculoskeletal symptoms and ensuring health care use and sick leave. Spine, Phila Pa. 2014; 30: 1550-1556.
31. Gaber M. Relationship among nurse's safety compliance, organizational safety climate, workers variables and job satisfaction at Zagazig Hospital. Life Science Journal. 2013; 10(12): 1041-1055.

32. Gad L. Study of the Administrative Duties of Baccalaureate Nursing Graduate Unit Manager. Master Thesis. Tanta University, Faculty of Nursing. 2013. 3-21.

33. Youssef N. Common Occupational Hazards Facing Nursing Staff at Tanta University Hospital. Master Thesis. Tanta University, Faculty of Nursing. 2017. 1-20.

34. Neves H, Souza A, Medeiros M, Munari D, Ribeiro L and Tiplle A. Safety of nursing staff and determinants of adherence to personal protective equipment. Rev Latino Am Enfermagem. 2011; 19(2): 354-61.

35. White J. The Impact Of Charge Nurse Transformational Leadership Workshops In Reducing Patient Falls. Doctor of Nursing Practice. Capella University, School of Nursing and Health Sciences. 2017; 10-15.

36. Abd Elaziz. Effect Of Training On The Head Nurses Managerial Skills Related To The Organizing And Directing. 


\section{Tanta Scientific Nursing Journal}

Master Thesis. Ain Shams University, Faculty of Nursing; 2010.

37. Clark S. The relationship between safety climate and safety performance:

A meta-analytic review. Journal of Occupational Health Psychology. 2016; 11(4): 315-327.

38. Sabra H and Morsy S. Occupational health hazards among nurses at Quena University Hospital. IOSR Journal of Nursing and Health Science (IOSRJNHS). 2016; 5(3): 28-34.

39. El-Atroush H. Work Related Hazards Facing Nurse Interns in ICU: A Program for Protection at Mansoura University Hospitals. Doctoral Thesis. Zagazig University, Faculty of nursing. 2010. 8-60.

40. Gammon J, Samuel H and Gould D. A review of the evidence for suboptimal compliance of healthcare practitioners to standard/universal infection control precautions. Journal of Clinical Nursing. 2017; 17(2):157-167.

41. Labrague L, Rosales $\mathrm{R}$ and Tizon M. Knowledge of and compliance with standard precautions among student nurses. International Journal of Advanced Nursing Studies. 2012; 1(2): 84-97.

42. Adly R, Amin F and Abd El Aziz M. Improving nurses' compliance with standard precautions of infection control in pediatric critical care units. World Journal of Nursing Sciences. 2014; 3(5): 01-09.

43. Nkoko L, Spiegel J, Parent S and Yassi A. Reducing the risks to health care workers from blood and body fluid exposure in a small rural hospital in Thabo-mosfutsanyana, South Africa. 2014; 62 (9): 382-8.

44. Aluko O, Adebayo E, Adebisi F, Abidoye A and Popoola B. A survey on knowledge, attitudes and perceptions of occupational hazards and safety practices in Nigeria health care workers. BMC. 2016; 10: 1186- 1880.

45. El Ashmawy E. Occupational Safety Strategies For Controlling And Management Of Needle Stick Injuries Among Nurses At Student University Hospital. Doctoral Thesis. Tanta University, Faculty of Nursing. 2017; 3-33.

46. Niu S. Occupational safety and health in the health care sector. African Newsletter on Occupational Health and Safety. 2015; 10:56 - 59.

47. Katz-Navon T, Naveh E and Stern Z. Safety climate in health care organizations: A multidimensional approach. Academy of Management Journal. 2015; 48(6): 1075-1089. 